\title{
Adoption of new silvicultural methods in Mediterranean forests: the influence of educational background and sociodemographic factors on marker decisions
}

\author{
Andrés Bravo-Oviedo ${ }^{1}$ (D) Maurizio Marchi ${ }^{2}$ (D) Davide Travaglini $^{3} \cdot$ Francesco Pelleri $^{3} \cdot$ Maria Chiara Manetti $^{3}$. \\ Piermaria Corona ${ }^{3} \cdot{\text { Fátima } \mathrm{Cruz}^{5} \cdot \text { Felipe Bravo }^{6} \text { (D) } \cdot \text { Susanna Nocentini }}^{4}$
}

Received: 26 June 2019 / Accepted: 23 March 2020 / Published online: 19 May 2020

(C) INRAE and Springer-Verlag France SAS, part of Springer Nature 2020

\begin{abstract}
- Key message The adoption of new silvicultural methods and approaches requires an understanding of the differences between those and "old" or "conventional" approaches, along with extensive training to break previous knowledge bias. - Context Forestry is in transition towards ecosystem-based management, and new silvicultural approaches are appearing worldwide. However, the adoption of an alternative silvicultural approach is difficult in practice.

- Aims We analyzed the effect of forestry background and demographic variables (gender and age) of 24 raters on the application of the systemic approach (SA) and the conventional approach (CA) in the Northern Apennines (Italy) and compared this with tree marking performed by experts.
\end{abstract}

\footnotetext{
Handling Editor: Marco Ferretti

Contribution of co-authors ABO: designed the marking study, analyzed the data and wrote the manuscript.

MM: designed the marking study and wrote the manuscript.

DT: designed the marking study, contributed to description of traditional methods and commented the manuscript.

FP: designed the marking study and installed the martelloscope, commented the manuscript.

MCM: designed the marking study and installed the martelloscope, commented the manuscript.

PC: contribution to description of systemic silviculture and discussion.

FC: contribution to analyses of sociodemographic variables, results, and discussion.

FB: contribution to analyses of martolloscope data, results, and discussion.

$\mathrm{SN}$ : contribution to description of systemic silviculture and discussion.
}

Electronic supplementary material The online version of this article (https://doi.org/10.1007/s13595-020-00947-z) contains supplementary material, which is available to authorized users.

Andrés Bravo-Oviedo

bravo@mncn.csic.es

1 Department of Biogeography and Global Change, National Museum of Natural Sciences, CSIC C/ Serrano, 115bis, 28006 Madrid, Spain

2 Institute of Biosciences and BioResources (IBBR), Florence division, Via Madonna del Piano 10, I-50019 Sesto Fiorentino (Firenze), Italy

3 Research Centre for Forestry and Wood (CREA), Viale S. Margherita, 80, 52100 Arezzo, Italy
4 Department of Agriculture, Food, Environment and Forestry (DAGRI), Via San Bonaventura 13, Florence 50145, Italy

5 University of Valladolid, Department of Psychology and Sustainable Forest Management Research Institute (iuFOR, UVa-INIA), Avenida de Madrid, 50, 34004 Palencia, Spain

6 Departamento de Producción Vegetal y Recursos Forestales and Instituto Universitario de Investigación en Gestión Forestal Sostenible (iuFOR, UVa-INIA), Universidad de Valladolid, Avenida de Madrid, 57, 34004 Palencia, Spain 
- Methods Data were analyzed as raters' departures from experts' selections at the stand and the individual tree level. The probability of tree selection was also calculated.

- Results At the stand level, raters with forestry background performed the SA as if they were marking for crown thinning, whereas the CA was less intense than experts' crown thinning. Non-foresters differentiated poorly between the SA and the CA. At the individual tree level, background and gender affected tree selection.

- Conclusion The adoption of the SA as a silvicultural system may be conditioned by previous knowledge. The difference between SA and CA remains unclear when it comes to non-foresters. Gender was a more important variable than age in selecting which trees would be harvested.

Keywords Applied forest ecology $\cdot$ Alternative forestry $\cdot$ Stand structure $\cdot$ Thinning $\cdot$ Marteloscope

\section{Introduction}

Forestry is facing a changing paradigm of concepts and procedures. Guidelines about forest management and silviculture emphasize the role of social and ecological values as well as the economic outcomes of forests (Angelstam et al. 2011; FOREST EUROPE 2015). Examples of such transition include changes in the orientation of traditional forest management textbooks that move from the regulation and valuation of timber to the sustainment of ecological, economic, and social values (e.g., Davis et al. 1951, 2001). A similar pathway is followed by silviculturists who claim that the practice of silviculture must be considered as applied forest ecology (Smith et al. 1996; Ashton and Kelty 2018). The reasons behind this conceptual change encompass the global environmental change and loss of biodiversity (Cardinale et al. 2012; Marchetti et al. 2014; FOREST EUROPE 2015)

There are economic, cultural, administrative, and educational challenges that impede the implementation of new paradigms in operational forestry. Studies documenting the longterm response to alternative silvicultural treatments in terms of the full suite of ecosystem goods and services are relatively scarce (Puettmann et al. 2015).

Stocking control is one of the main operational tools used to achieve silvicultural objectives, where harvestable trees are selected and marked on the field. Behind the process of tree selection underlie interpretations that depend on educational background, professional expertise, personal choices, and training of people who make and implement decisions (Spinelli et al. 2016; Vítková et al. 2016; Pommerening et al. 2018).

Gender and age are seen as important factors that influence differences in forestry management activities (Lidestav and Ekström 2000; Eggers et al. 2014). Eggers et al. (2014) claim that "older owners were less likely to harvest or actively manage their forests than younger owners" (p. 1696). Other studies show that gender, as a sociocultural and structural category factor sensu Harding (1986), can affect the self-evaluation of forestry competence and perceptions about the use of forest products (Lidestav and Ekström 2000; Sunderland et al. 2014; Follo et al. 2017). Studying male and female forest owners, Lidestav and Ekström (2000) found that the latter consider their own knowledge in forestry management considerably lower, whereas according to Umaerus et al. (2019), males focus more on production and females on preservation. Despite these differences, there is still a lack in the literature on how gender can influence decisionmaking in forestry.

Experimental layouts used to disentangle gender perceptions about forestry-related issues have been carried out based on questionnaires (e.g., Eggers et al. 2014; Sunderland et al. 2014; Villamor et al. 2014), but operational experiments on the field where decisions are made based on previous experience or training are scarce.

Marteloscopes are training areas where forestry students and practitioners mark trees according to silvicultural objectives (Schuck et al. 2015). They are promising tools for complex forest management systems (Pretzsch and Zenner 2017) and have been used to analyze the inter-rater agreement when new silvicultural methods are applied (Pommerening et al. 2018). Vítková et al. (2016) tested the agreement in tree marking among raters with different levels of expertise, ranging from experienced foresters to non-foresters. Their findings suggested that the degree of expertise is an obstacle to learning and applying new silvicultural methods. Inter-rater agreement informs us to what extent a group of trainees agrees to perform a particular task; however, it does not tell us if there is an agreement with the expected outcome proposed by an expert or trainer.

Expertise is usually gained by practicing one particular task through time along with a combination of training, ability, and effort (Bourne et al. 2014). We hypothesized that differences in educational background or training may affect the degree of expertise within a professional group. This means that the changes in the academic paradigm of forestry, as described above, would affect the performance of foresters.

The research objective of this study was to analyze the resulting forest structure after marking candidate trees to be 
removed, while following two different silvicultural alternatives: systemic silviculture (Ciancio and Nocentini 2011; Nocentini et al. 2017) and the conventional or "business as usual" approach. The influence of sociodemographic factors (forest background, age, and gender) in the process was taken into account. The main working assumption was that the higher the agreement and the lower the difference between the selection of trees by raters and experts, the higher the likelihood of the practical implementation of a new silvicultural approach would be. We tested the validity of the following statements:

1. Raters with forestry background should distinguish between the two silvicultural methods better than markers without forestry background. Agreement in tree selection will be different between the two silvicultural approaches but not within raters with the same background.

2. Sociodemographic features, such as gender and age, modulate marking intensity, tree selection, and agreement.

\section{Materials and methods}

\subsection{Marteloscope description and marker selection}

A marteloscope is a training area located in a forest where foresters may practice virtual tree marking. The marteloscope used in our study was located in the Appennino Pistoiese (Fig. 1) covering an area of $6400 \mathrm{~m}^{2}$ and divided in $1620 \times$
20 m quadrants (Q1-Q16) to facilitate the marking procedure (Bravo-Oviedo et al. 2020). The stem density in the marteloscope was $1278 \mathrm{stems} \mathrm{ha}^{-1}$, ranging from 775 to 2525 stems ha $^{-1}$ within the 16 quadrants. The standing timber volume was $332.1 \mathrm{~m}^{3} \mathrm{ha}^{-1}$, ranging between 94.3 and $975.2 \mathrm{~m}^{3} \mathrm{ha}^{-1}$ within quadrants (Table 1).

Two different forest types (FT), based on stand composition and structural stages, were selected to test the conventional and systemic approach (CA and SA, respectively). The first FT (FT-1) was a 50-year-old afforestation of Norway spruce (Picea abies L.) mixed with other broadleaved trees, mainly European beech (Fagus sylvatica L.), in quadrants $10,11,13,14$, and 15 . The second FT (FT-2) was a broadleaved-mixed and broadleaved-conifer mixture in the understory reinitiation phase (Oliver and Larsson 1990), dominated by beech, sycamore (Acer pseudoplatanus L.), goat willow (Salix caprea L.), and silver fir (Abies alba Mill.) located in quadrants $1,2,4,5,6,7,8,9,12$, and 16 .

The selection of participants was based on educational background (forestry vs. non-forestry), age (above and below 40 years old), and gender (female and male) ( 3 raters $\times 2$ backgrounds $\times 2$ age classes $\times 2$ genders $=24$ participants). The 40 year-old age threshold was selected because we considered that foresters who obtained their degree in the last 20 years would be more familiar with terms related to sustainable forest management, global change, and biodiversity loss. These participants started their forestry studies after the Rio Conference (average starting year of forestry studies in participants $<40$ years of age was 2003), whereas older foresters started their studies before
Fig. 1 Stem map and DBH histogram of the Abetone marteloscope. The circle's size is proportional to tree DBH
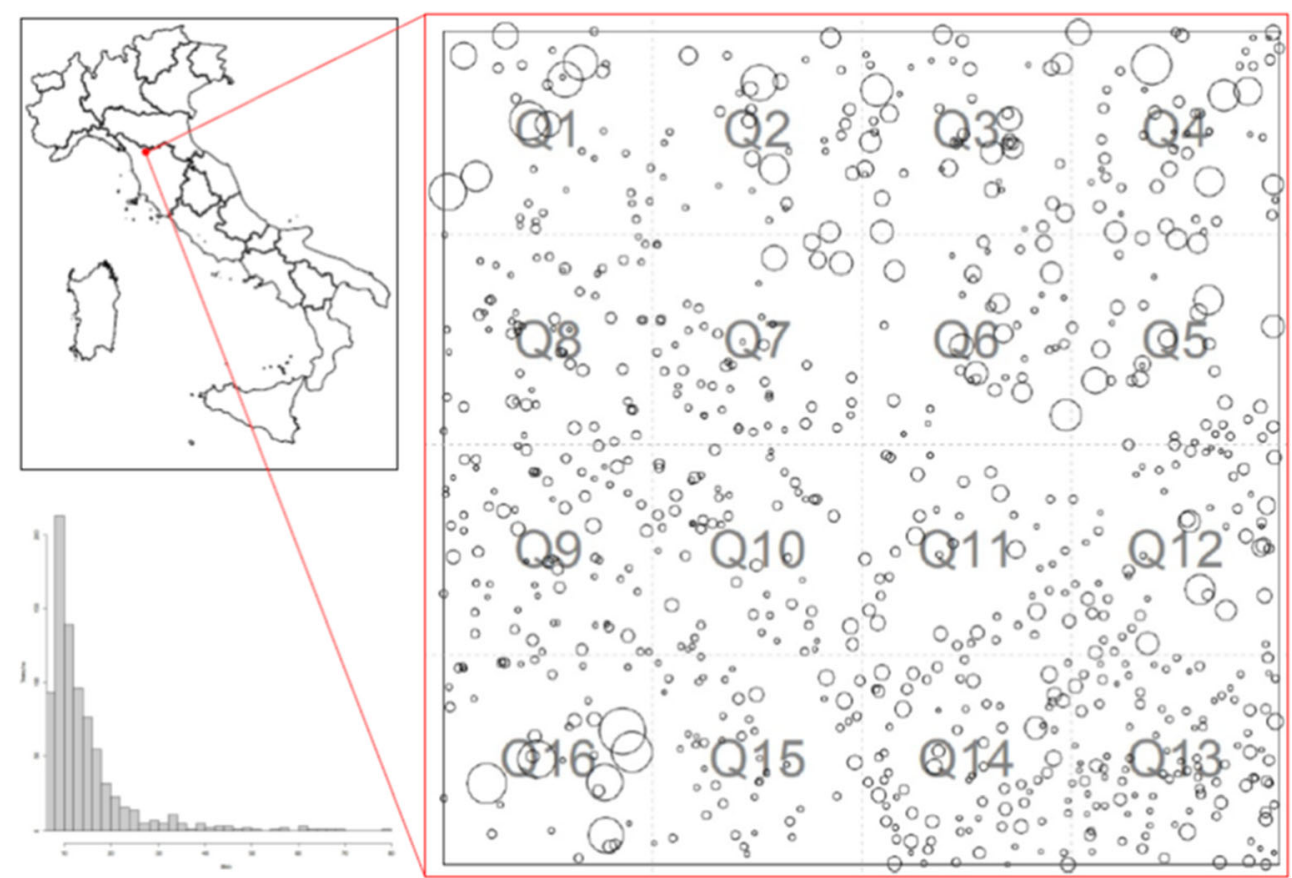
Table 1 Abetone marteloscope stand-level variables by quadrants and tree species

\begin{tabular}{|c|c|c|c|c|c|c|c|c|c|}
\hline Quadrant & Species & Number & $\mathrm{BA}$ & $\mathrm{V}$ & Quadrant & Species & Number & $\mathrm{BA}$ & $\mathrm{V}$ \\
\hline \multirow[t]{9}{*}{1} & Abies alba & 200 & 47.9 & 711.2 & \multirow[t]{7}{*}{9} & Acer pseudoplatanus & 500 & 9.2 & 54.1 \\
\hline & Acer pseudoplatanus & 300 & 4.5 & 15.9 & & Salix caprea & 400 & 6.1 & 34.6 \\
\hline & Fagus sylvatica & 275 & 3.4 & 22.5 & & Picea abies & 250 & 5.8 & 31.4 \\
\hline & \multirow[t]{4}{*}{ Laburnum anagyroides } & \multirow[t]{4}{*}{100} & \multirow[t]{4}{*}{0.8} & \multirow[t]{4}{*}{2.7} & & Fagus sylvatica & 350 & 4.0 & 21.8 \\
\hline & & & & & & Fraxinus excelsior & 100 & 2.1 & 13.4 \\
\hline & & & & & & Sorbus aucuparia & 75 & 0.6 & 2.6 \\
\hline & & & & & & Larix decidua & 25 & 0.2 & 0.9 \\
\hline & Total quadrant 1 & 875 & 56.7 & 752.3 & & Total quadrant 9 & 1700 & 27.9 & 158.8 \\
\hline & Abies alba & 75 & 20.8 & 98.3 & 10 & Picea abies & 350 & 8.2 & 41.7 \\
\hline \multirow[t]{6}{*}{2} & Acer pseudoplatanus & 75 & 10.1 & 11.3 & & Acer pseudoplatanus & 300 & 4.2 & 21.7 \\
\hline & Fagus sylvatica & 600 & 1.6 & 173.7 & & Salix caprea & 350 & 4.0 & 20.1 \\
\hline & \multirow[t]{3}{*}{ Laburnum anagyroides } & \multirow[t]{3}{*}{25} & \multirow[t]{3}{*}{0.2} & \multirow[t]{3}{*}{0.8} & & Fraxinus excelsior & 75 & 2.5 & 14.8 \\
\hline & & & & & & Fagus sylvatica & 225 & 2.3 & 11.9 \\
\hline & & & & & & Larix decidua & 50 & 1.9 & 12.1 \\
\hline & Total quadrant & 775 & 32.7 & 284.1 & & Prunus avium & 25 & 0.2 & 0.7 \\
\hline \multirow[t]{8}{*}{3} & Fagus sylvatica & 975 & 41.5 & 403.0 & & Total quadrant 10 & 1375 & 23.3 & 123.0 \\
\hline & Sorbus aucuparia & 75 & 4.1 & 29.1 & 11 & Picea abies & 400 & 13.5 & 77.6 \\
\hline & Acer pseudoplatanus & 25 & 2.5 & 26.0 & & Fagus sylvatica & 350 & 4.0 & 18.6 \\
\hline & \multirow[t]{4}{*}{ Abies alba } & \multirow[t]{4}{*}{25} & \multirow[t]{4}{*}{0.4} & 1.2 & & Fraxinus excelsior & 75 & 3.5 & 23.1 \\
\hline & & & & & & Acer pseudoplatanus & 100 & 2.3 & 12.0 \\
\hline & & & & & & Laburnum anagyroides & 50 & 0.8 & 2.9 \\
\hline & & & & & & Prunus avium & 25 & 0.3 & 1.0 \\
\hline & Total quadrant 3 & 1100 & 48.5 & 459.4 & & Total quadrant 11 & 1000 & 24.4 & 135.3 \\
\hline 4 & Fagus sylvatica & 1075 & 30.1 & 280.8 & 12 & Fagus sylvatica & 775 & 25.7 & 226.7 \\
\hline & Acer pseudoplatanus & 75 & 11.9 & 112.0 & & Picea abies & 325 & 6.6 & 35.8 \\
\hline & Abies alba & 75 & 11.0 & 138.2 & & Salix caprea & 50 & 3.0 & 25.1 \\
\hline & Sorbus aucuparia & 25 & 0.5 & 3.2 & & Sorbus aucuparia & 50 & 0.8 & 4.7 \\
\hline & & & & & & Abies alba & 25 & 0.7 & 3.8 \\
\hline & & & & & & Fraxinus excelsior & 50 & 0.6 & 4.4 \\
\hline & & & & & & Larix decidua & 25 & 0.3 & 1.9 \\
\hline & Total quadrant & 1250 & 53.5 & 534.2 & & Total quadrant 12 & 1300 & 37.7 & 302.3 \\
\hline 5 & Fagus sylvatica & 800 & 30.3 & 281.8 & 13 & Picea abies & 1025 & 22.5 & 124.8 \\
\hline & Abies alba & 75 & 8.2 & 92.6 & & Fagus sylvatica & 1350 & 14.4 & 75.7 \\
\hline & & & & & & Larix decidua & 75 & 1.6 & 9.9 \\
\hline & & & & & & Fraxinus excelsior & 25 & 1.0 & 5.7 \\
\hline & & & & & & Salix caprea & 50 & 0.6 & 3.4 \\
\hline & Total quadrant 5 & 875 & 38.5 & 374.4 & & Total quadrant 13 & 2525 & 40.1 & 219.6 \\
\hline 6 & Fagus sylvatica & 725 & 25.8 & 241.2 & 14 & Picea abies & 1050 & 25.4 & 145.3 \\
\hline & Acer pseudoplatanus & 50 & 8.2 & 85.0 & & Larix decidua & 200 & 9.6 & 66.6 \\
\hline & Picea abies & 75 & 1.4 & 6.8 & & Fagus sylvatica & 575 & 6.8 & 43.8 \\
\hline & Laburnum anagyroides & 25 & 0.2 & 0.7 & & Fraxinus excelsior & 75 & 1.8 & 11.3 \\
\hline & Sorbus aucuparia & 25 & 0.1 & 0.4 & & Acer pseudoplatanus & 25 & 0.4 & 2.6 \\
\hline & & & & & & Salix caprea & 25 & 0.4 & 1.9 \\
\hline & Total quadrant 6 & 900 & 35.8 & 334.1 & & Total quadrant 14 & 1950 & 44.4 & 271.5 \\
\hline 7 & Fagus sylvatica & 300 & 12.6 & 112.0 & 15 & Picea abies & 300 & 7.0 & 39.9 \\
\hline & Acer pseudoplatanus & 425 & 5.6 & 28.9 & & Fagus sylvatica & 475 & 4.4 & 20.3 \\
\hline & Picea abies & 200 & 2.9 & 10.8 & & Acer pseudoplatanus & 250 & 4.3 & 22.6 \\
\hline & Salix caprea & 125 & 1.8 & 8.2 & & Salix caprea & 150 & 1.8 & 9.9 \\
\hline & Laburnum anagyroides & 100 & 1.3 & 5.6 & & Sambucus nigra & 25 & 0.3 & 0.9 \\
\hline & Fraxinus excelsior & 75 & 1.1 & 6.6 & & Fraxinus excelsior & 25 & 0.2 & 0.8 \\
\hline & Total quadrant 7 & 1225 & 25.2 & 172.1 & & Total quadrant 15 & 1225 & 18.0 & 94.3 \\
\hline 8 & Acer pseudoplatanus & 1175 & 18.5 & 103.6 & 16 & Abies alba & 150 & 54.3 & 880.4 \\
\hline & Fagus sylvatica & 50 & 2.8 & 1.6 & & Fagus sylvatica & 475 & 10.0 & 73.1 \\
\hline & Fraxinus excelsior & 50 & 0.7 & 3.3 & & Acer pseudoplatanus & 200 & 2.6 & 16.1 \\
\hline & Salix caprea & 175 & 0.4 & 14.5 & & Picea abies & 75 & 0.8 & 3.7 \\
\hline & & & & & & Salix caprea & 25 & 0.3 & 1.9 \\
\hline & Total quadrant 8 & 1450 & 22.3 & 123.1 & & Total quadrant 16 & 925 & 68.0 & 975.2 \\
\hline
\end{tabular}

Number stems ha ${ }^{-1}, B A$ basal area $\left(\mathrm{m}^{2} \mathrm{ha}^{-1}\right), V$ volume $\left(\mathrm{m}^{3} \mathrm{ha}^{-1}\right)$ 
the Rio Conference (average starting year was 1987). The number of participants per group combination (gender-background and age-background) was kept low ( 6 participants $\times 4$ groups) in order to avoid interferences among raters working in the same quadrant (Vítková et al. 2016).

Before the marking, participants were asked to fill a questionnaire that would allow us to characterize the groups according to the level of studies, their relation to the forestry sector, and their level of familiarity with marking trees or the SA (supp. information). In the rest of the paper, participants will be referred to as raters in order to be consistent with previous forestry and statistical studies (Tanner and Young 1985; Fleiss et al. 2013; Pommerening et al. 2018).

\subsection{Marking procedure}

\subsubsection{Experts}

We obtained a benchmark against which we compared the raters' tree selection by asking four foresters with expertise in SA and CA to mark trees following formal academic prescriptions. Experts were also asked to mark trees according to two traditional thinning methods (Piussi 1994): crown and low thinning. The aim was to elucidate if the performance of raters with forestry background was affected by previous knowledge. A full description of all methods can be found in Table 4 in the annex section.

\subsubsection{Raters}

$\mathrm{CA}$ and SA were taught and performed independently. Raters were asked to start the marking exercise without contact with other participants to avoid selecting a tree already chosen by another participant. Raters started in different quadrants to avoid "memory" bias caused by remembering previously selected trees. All raters were equipped with a portable version of Smartelo® software (Rodriguez de Prado et al. 2017), loaded on their smartphone or tablet, in order to record the trees selected for harvest.

\subsection{Silvicultural approaches}

\subsubsection{CA}

The CA, as described in the current forest management plan, aims to improve the growing conditions and stimulate the growth of selected "crop trees" that are valuable from a technological point of view or important for increasing biodiversity (e.g., fruit bearing trees for bird diversity, etc.). Additionally, this approach involves stand tending activities so as to reduce the trees' susceptibility to pest outbreaks and/ or reduce the fuel load.

\subsubsection{SA}

The SA adheres to the five silvicultural principles for alternative management systems described in Puettmann et al. (2015): partial harvest, natural regeneration, structural heterogeneity, increased tree species richness, and avoidance of intensive operations. From a tree marking point of view, the SA does not prescribe a predetermined post-harvest composition or stand structure. The only prescription is that the volume of a stand should never fall below a minimum standing growing stock ranging from 100 to $150 \mathrm{~m}^{3} \mathrm{ha}^{-1}$ for forests with dominant light-demanding species, to $300-350 \mathrm{~m}^{3} \mathrm{ha}^{-1}$ for dominant shade-tolerant species, as in the case of our study. In the presence of uniform stands, marking should aim at creating the conditions for the establishment of natural regeneration by gradually opening small gaps in the canopy, based on the principle of increasing structural and compositional complexity.

\subsection{Data analyses}

\subsubsection{Post-harvest stand characterization}

The ratio of the percentage of the basal area removed to the percentage of the number of stems removed was used to determine the type of marking (TT, Eq. 1) following the logic proposed by Kerr and Haufe (2011):

$\mathrm{TT}=\frac{\% \mathrm{BA}_{\text {removed }}}{\% \mathrm{~N}_{\text {removed }}}$

where $\% \mathrm{BA}_{\text {removed }}$ is the percentage of basal area removed and $\% \mathrm{~N}_{\text {removed }}$ is the percentage of number of stems removed. Values higher than or equal to 1.1 indicated tree marking that could be assimilated to crown thinning, while values lower than or equal to 0.9 indicated low thinning (Kerr and Haufe 2011). This index is the inverse of that proposed by Kassier (1993) and used elsewhere. We prefer Kerr and Haufe's formulation because higher values of the index indicate higher marking intensity.

\subsubsection{Stand level analyses}

The marking performance ratio $\left(\mathrm{TTP}_{x, y}\right)$ was calculated for all silvicultural approaches and raters grouped by background alone, background and gender, and background and age class. Raters' performance was analyzed in terms of departure from the experts' marking by using the ratio of the marking type index, obtained after the raters' selection, to the marking type index obtained after expert marking (Eq. 3).

$\mathrm{TP}_{\mathrm{CA}, \mathrm{SA}}=\frac{\mathrm{TT}_{\text {rater }(\mathrm{CA}, \mathrm{SA})}}{\mathrm{TT}_{\text {expert }(\mathrm{CA}, \mathrm{SA})}}$ 
Table 2 Generic structure of a $2 \times 2$ table used to calculate the agreement in tree selection between the expert and the $k$ th rater

\begin{tabular}{lllll}
\hline & & $\begin{array}{l}\text { Rater } k \\
\text { Marked }\end{array}$ & Not marked & \\
\hline \multirow{2}{*}{ Expert } & Marked & $p_{11}$ & $p_{12}$ & $p_{1+}$ \\
& Not marked & $p_{21}$ & $p_{22}$ & $p_{2+}$ \\
& $p_{+1}$ & $p_{+2}$ & 1 \\
\hline
\end{tabular}

Notice that the expert should be always placed in the row of the $m$ possible tables (Bishop et al. 2007) where $j=1, \ldots ., m$ and $p_{i j}$ is the observed proportion

where $\mathrm{TP}_{\mathrm{CA}}, \mathrm{SA}$ is the marking performance, $\mathrm{TT}_{\text {rater(CA, } \mathrm{SA})}$ is the marking type performed by raters, and $\mathrm{TT}_{\text {expert(CA, SA) }}$ is the marking type obtained after expert marking by the conventional or systemic approaches, SA and CA, respectively. A non-parametric Wilcoxon signed rank test was used to test if any of the ratios would differ significantly from one. As the forest types were identified before the harvest (FT-1 and FT2 ), analyses at the stand level were performed both for the entire marteloscope and by forest types.

Information about the factors influencing the marking type was assessed using a nested linear model. Marking intensity, or the log-transformed value of marking intensity, was fitted with the silvicultural method, the type of marker (expert vs. rater), the background of raters (foresters vs. non-foresters), the gender and age cohort of participants, and the interaction between the method and the participant as factors. Background, age, and gender were nested within the rater. We fitted several models including background as a nested factor alone, a demographic model with gender and age as nested factors, and a full model with all nested effects including the initial basal area of each quadrant as a covariate (Eq. 4).

$$
\begin{aligned}
y_{i j, s a b(i)}= & \beta_{0}+\beta_{1} x_{i}+\beta_{2} x_{j}+\beta_{3} x_{i j}+\beta_{4} x_{s(i)}+\beta_{5} x_{a(i)} \\
& +\beta_{6} x_{b(i)}+\varepsilon_{i j}
\end{aligned}
$$

where $x_{i}$ is marker type (expert vs. rater), $x_{j}$ is the silvicultural approach applied (SA vs. CA), $x_{s}$ is the gender group each participant belonged to, $x_{a}$ is the age effect for each participant, and $x_{b}$ is the background group each participant belonged to.

\subsubsection{Individual tree level}

Probability of tree selection The probability of a tree to be marked with the SA and the CA was assessed by comparing the odds ratio from a logistic model that accounted for the main factors associated with the selection process, including tree size (diameter at breast height). A linearized main effects logit model was used (Eq. 5):
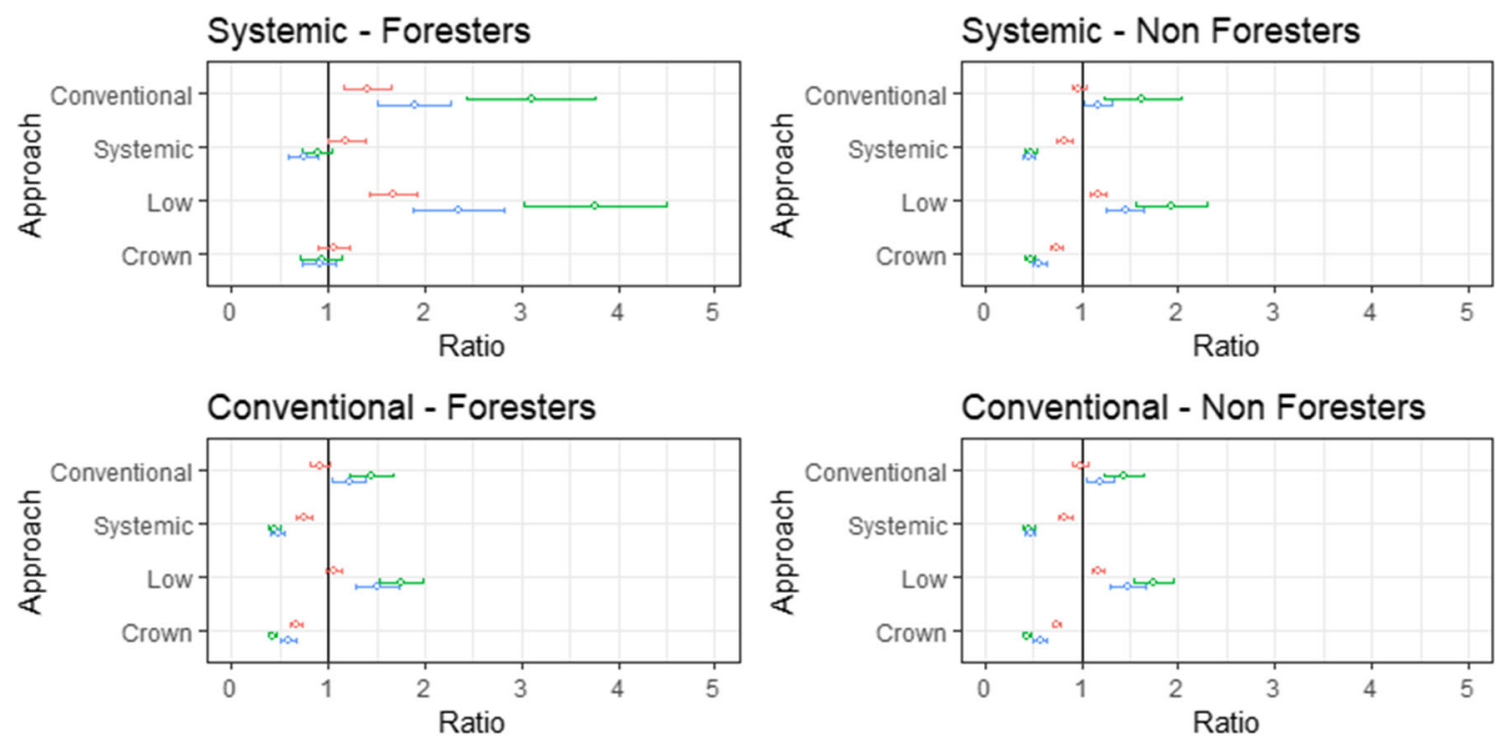

Quadrants $\multimap$ Forest Type $1 \multimap$ Forest Type $2 \multimap$ All quadrants

Fig. 2 Rater-expert ratio by background after performing SA (upper panel) and CA (bottom panel). The red line represents FT-1, the green line is FT-2, and the blue line represents all quadrants 

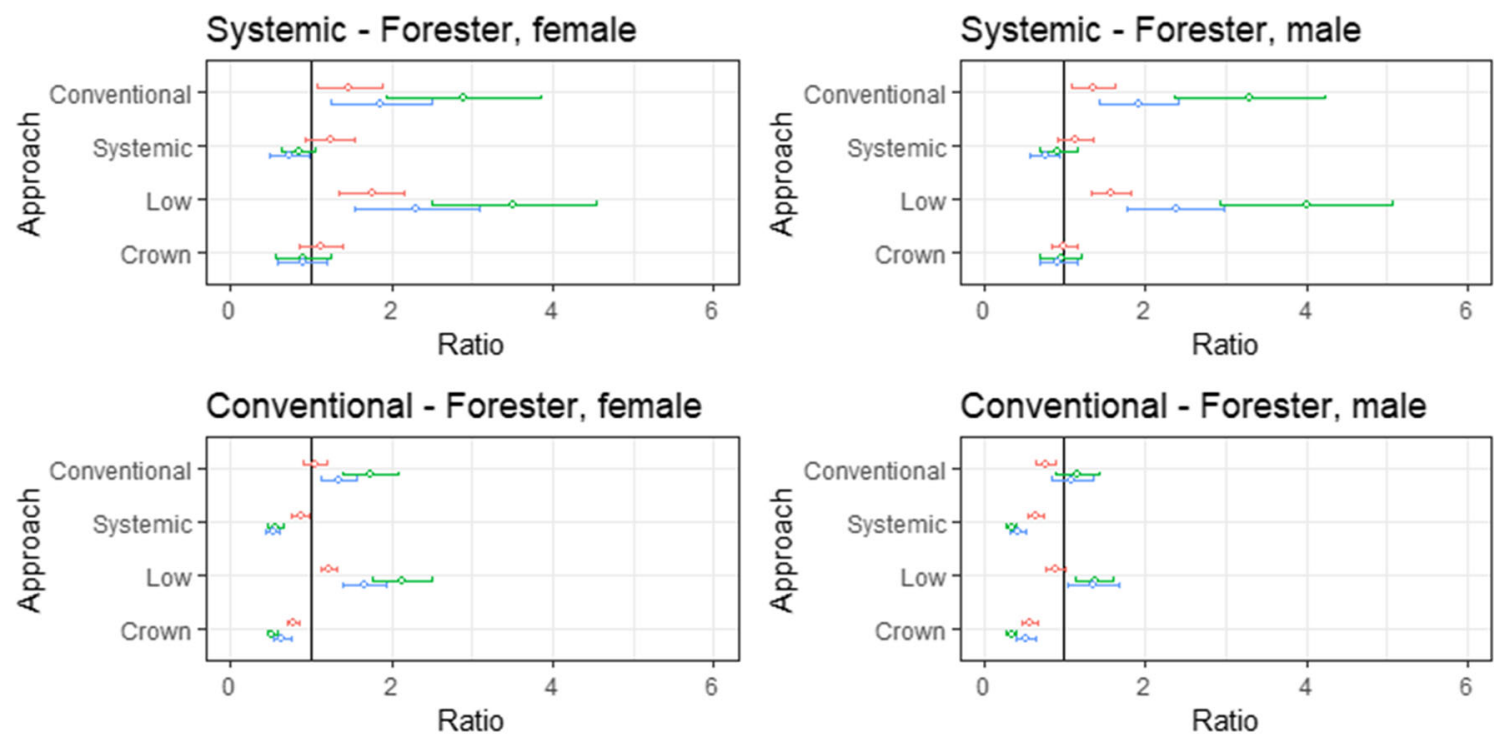

Quadrants $\multimap$ Forest Type $1 \multimap$ Forest Type $2 \leadsto$ All quadrants

Fig. 3 Rater-expert ratio by background and gender after performing SA (upper panel) and CA (bottom panel). The red line represents FT-1, the green line is FT-2, and the blue line represents all quadrants

$\log \left\{\frac{p_{k}}{1-p_{k}}\right\}=\alpha+\beta_{0} x_{k}+\beta_{1} x_{i k}+\beta_{2} x_{m}+\beta_{3} x_{b}+\beta_{4} x_{s}$

$$
+\beta_{5} x_{a}
$$

Equation 5 is the log odds of selection versus non-selection in method $m$ of the $k$ th tree of the $i$ th species, when the $m$ th method was applied by people of the $b$ th background group, $s$ th gender, and $a$ th age. Then, we fitted and expanded the
Systemic - Forester, above 40

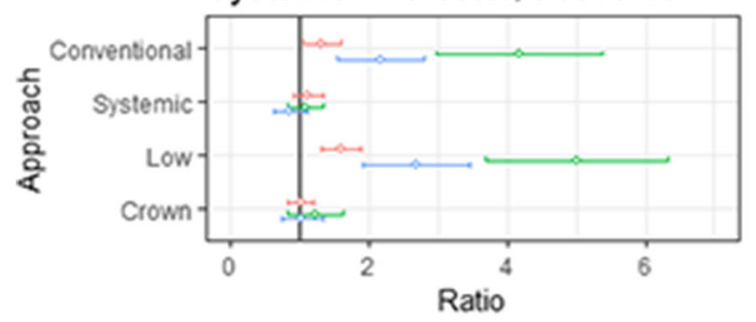

Conventional - Forester, above 40

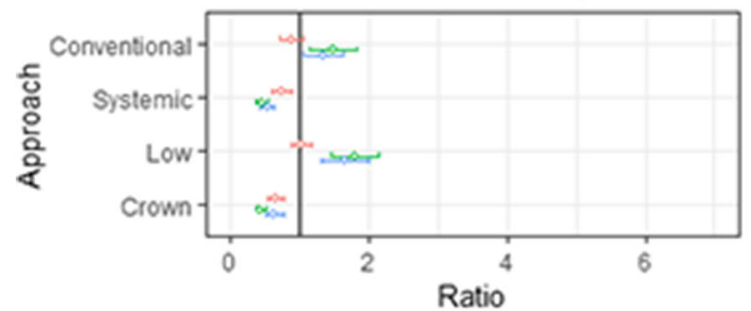

Systemic - Forester, under 40

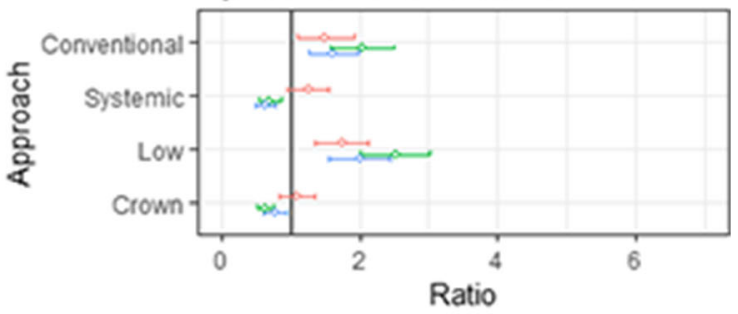

Conventional - Forester, under 40

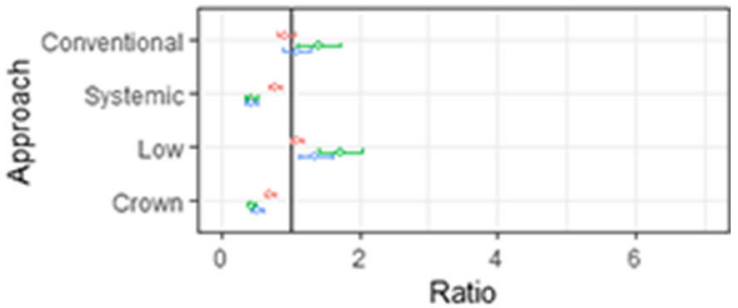

Quadrants $\rightarrow$ Forest Type $1 \multimap$ Forest Type $2 \multimap$ All quadrants

Fig. 4 Rater-expert ratio by background and age after performing SA (upper panel) and CA (bottom panel). The red line represents FT-1, the green line is FT-2, and the blue line represents all quadrants 
Fig. 5 Mean BA ratio value by type of participant and silvicultural approach. Letters indicate significant differences of least square means between groups

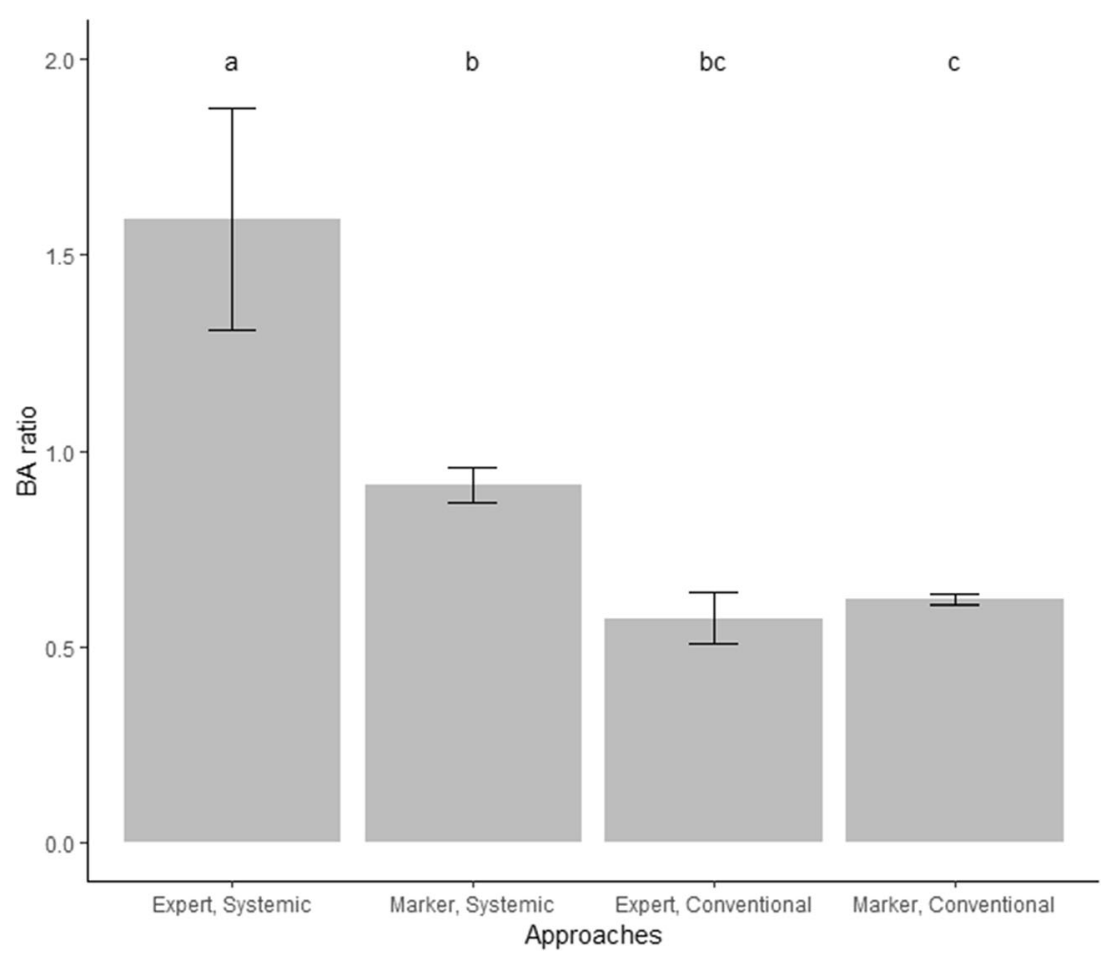

model with background, gender and background, and age interactions.

Ratios of the probability of selection by species to significant factors from Eq. 5 in the SA versus the CA were calculated. This analysis allowed inferring changes in the selection of species when SA and CA were used.

Agreement between the expert and the raters Inter-rater agreement among $m$ raters, when $m>2$, is usually calculated using the kappa statistic proposed by Fleiss (1971) or the exact kappa proposed by Conger (1980). Both kappa values are highly correlated and the selection of either or both depends on the research objectives. Bishop et al. (2007) proposed a method of conditional agreement, to measure the agreement of observers for one item that one of the observers classified in one of the categories tested. We applied this method to evaluate the agreement between $m$ raters conditional to the expert tree selection.

We started by calculating the general agreement between $m$ raters and the expert for CA and SA using the exact Fleiss' kappa [Eq. 6] by background, background and sex, and background and age for the each of $m$ possible $2 \times 2$ tables.

$K=\frac{\sum_{i} p_{i i}-\sum_{i} p_{i+} p_{+i}}{1-\sum_{i} p_{i+} p_{+i}}=\frac{\theta_{1}-\theta_{2}}{1-\theta_{2}}$ where $p_{i i}, p_{+i}$, and $p_{i+}$ are the main diagonal and marginal proportions shown in Table 2.

Afterwards, we computed the agreement of $m$ raters conditional to the expert tree selection using Eq. 6 and averaging the resulting $m K_{i}$ values.

$K_{i}=\frac{\left(\frac{p_{i i}}{p_{i+}}-p_{+i}\right)}{1-p_{+i}}=\frac{p_{i i}-p_{i+} p_{+i}}{p_{i+}-p_{i+} p_{+i}}$

The linear nested model and logistic function were fitted using SAS® V. 9.4 PROC MIXED and PROC LOGISTIC, respectively. General and conditional Fleiss' kappa were calculated in $\mathrm{R}$ ( $\mathrm{R}$ Core Team 2018) using the irr package (Gamer et al. 2019).

\section{Results}

\subsection{Stand level}

\subsubsection{Forestry background}

Raters with forestry background performed SA with an intensity compatible with crown thinning. The marking intensity of the SA performed by raters was slightly lower than that 
Fig. 6 Ratio of probability of tree selection between raters and experts. Values greater than 1 indicate that the probability of tree selection is higher in the rater than in the expert group. Solid line for male participants and dashed line for female participants
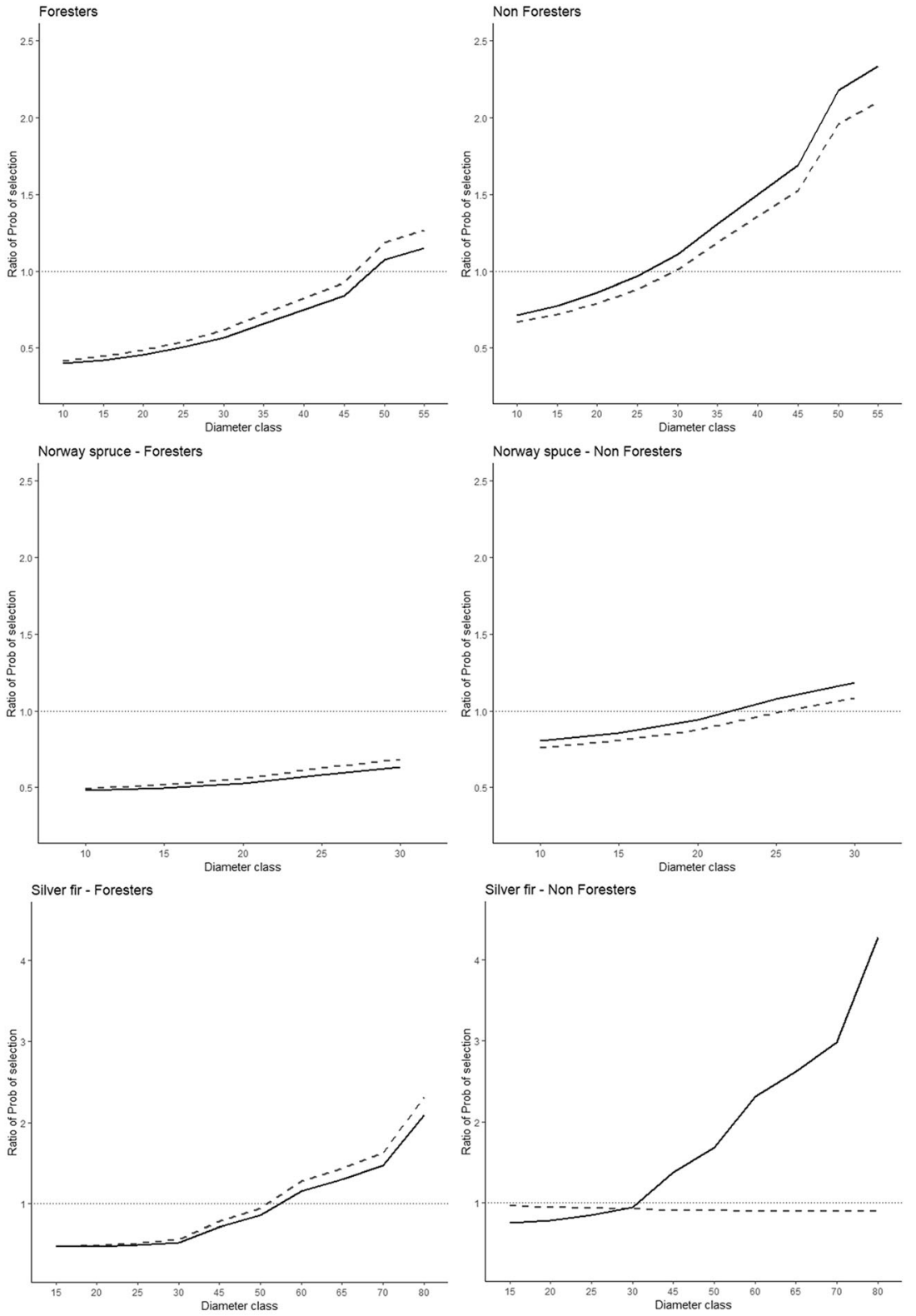

Table 3 Exact Fleiss' kappa values for within group agreement in each of the groups considered in the analyses

\begin{tabular}{llllll}
\hline Method & Group of raters & & & & \\
& Foresters & Female foresters & Male foresters & Foresters $>40$ years & Foresters $<40$ years \\
Conventional & 0.244 & 0.192 & 0.309 & 0.212 & 0.266 \\
Systemic & 0.062 & 0.054 & 0.045 & 0.074 & 0.041 \\
& Non-forester & Female non-foresters & Male non-foresters & Non-foresters $>40$ years & Non-foresters $<40$ years \\
Conventional & 0.235 & 0.249 & 0.228 & 0.266 & 0.213 \\
Systemic & 0.182 & 0.215 & 0.128 & 0.195 & 0.171 \\
\hline
\end{tabular}


Fig. 7 Inter-rater agreement (upper panels) and conditional agreement of marked trees (bottom panels) by background and gender
Fig. 8 Inter-rater agreement (upper panels) and conditional agreement of marked trees (bottom panels) by background and age

\section{Conventional}
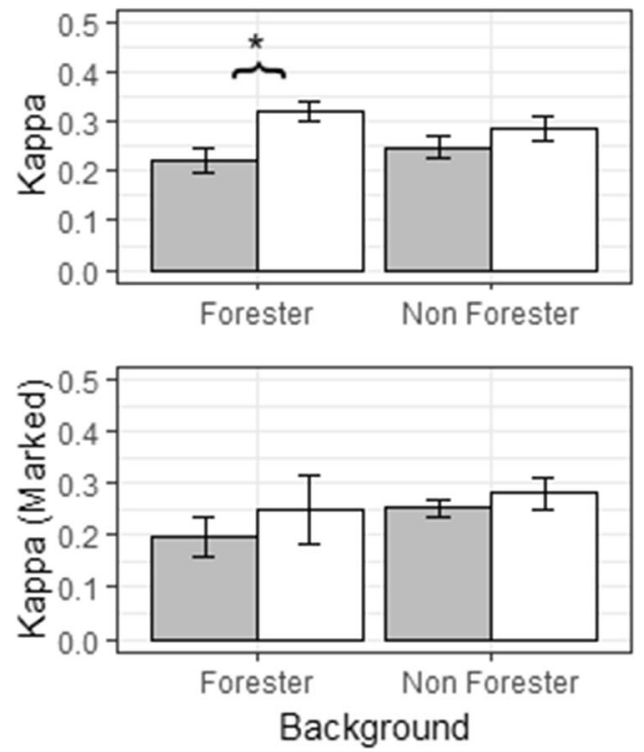

Gender

Female

\section{Systemic}
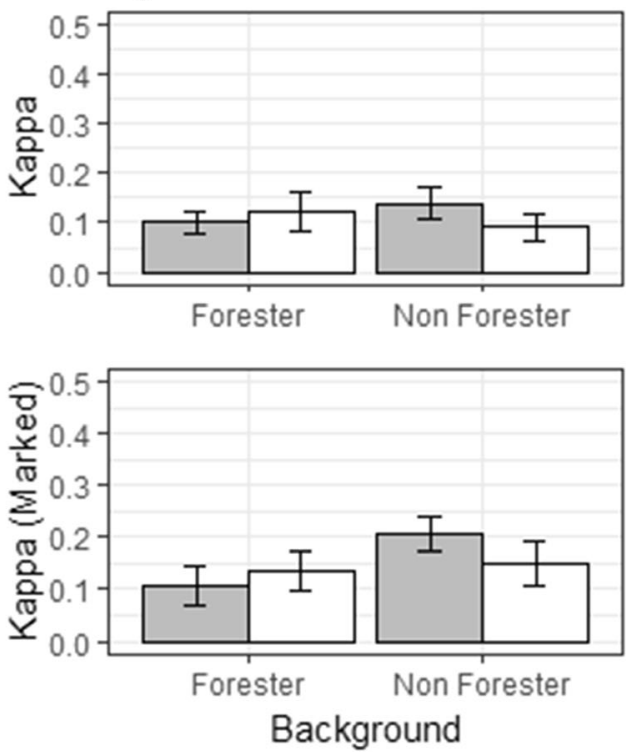

Background

\section{Conventional}
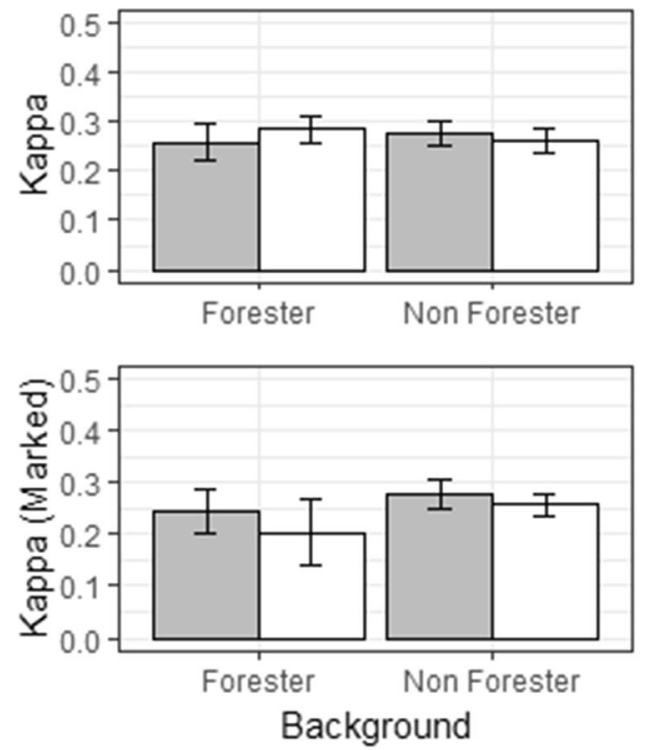
Male

\section{Systemic}
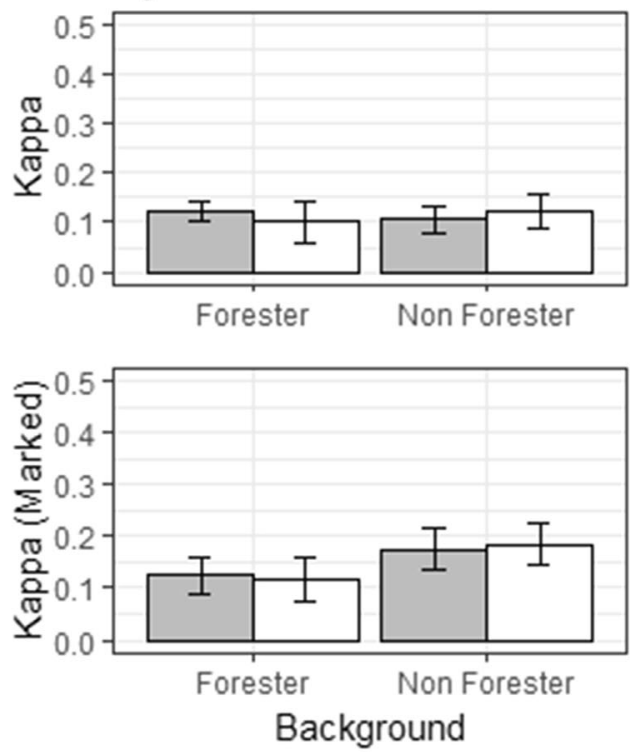

Age

Above 40 yrs Below 40 yrs 
performed by experts in forest type FT-2 and for the entire marteloscope, while it was 1.9 times higher in forest type FT1. The intensity of the SA performed by foresters in FT-2 was more than three times higher than that reached by experts in the CA and low thinning approaches (Fig. 2, upper panel). Non-foresters applied the SA and crown thinning less intensively than the experts, while the opposite was true for the CA and low thinning.

Raters with forestry background deviated from the expert's marking but showed low differences across forest types. The variability of marking intensities was also reduced compared with the application of the SA (Fig. 2, left panels). Nonforesters replicated in the CA the same pattern observed when they performed the SA, suggesting that they did not differentiate between the SA and the CA (Fig. 2, right panels). It is remarkable that raters from both backgrounds applied the CA in a similar manner as the experts.

\subsubsection{Gender and age effects}

Both female and male foresters applied a similar marking intensity in the SA compared with the SA and crown thinning marking intensity performed by experts. On the other hand, both gender groups applied a higher marking intensity in the CA compared with the CA and low thinning performed by experts (Fig. 3, upper panel). CA thinning was performed by male foresters in a similar manner that experts performed CA and low thinning marking (Fig. 3, right and bottom panel). Female foresters performed a more intense CA marking compared with the $\mathrm{CA}$ and low thinning performed by experts. This was more evident in quadrants dominated by native mixed-species (Fig. 3, bottom panels, FT-2). Female non-foresters applied the CA less intensively than the experts applied SA, whereas male nonforesters applied a more intense marking (Fig. 9 in the annex section, bottom panels).

Regarding age class, foresters with more experience matched the SA with crown thinning and SA performed by the experts, whereas the CA deviated from experts' marking (Fig. 4, left panels). However, young foresters performed in a reverse way as they marked the CA more closely to expert decisions, whereas the SA was loosely related to experts' decisions (Fig. 5, right panels). Both age groups of non-experts showed the same pattern when their performance was compared with that of experts, with low variability between approaches (Fig. 9 in the annex section).

\subsubsection{Stand-level nested model}

The best model included the silvicultural approach, the type of participant (rater or expert), interaction between criteria, and type of participant as main effects and gender and background as nested effects (Table 5 in the annex section). There were strong differences between silvicultural approaches and participant types. Experts performed a more intense marking than raters did, and the SA was significantly more intense than the CA. Raters performed a more intense marking when they were requested to apply the SA than the CA. However, both methods were similar to the CA used by experts. The highest intensity was recorded when experts applied the SA (Fig. 5). Female raters marked in a similar manner to experts, but slightly more intense than male raters. The background analyses showed that foresters and experts marked in a similar manner in terms of intensity, whereas nonforesters marked with a significantly lower intensity (Fig. 11 in the annex section).

\subsection{Individual-tree level}

\subsubsection{Probability of selection}

The probability of selection of a tree in the SA and CA was a function of the interaction between gender and group; the gender effect was stronger in the CA, whereas the group effect was more important in the SA (Table 6 in the annex section, best models). Age was not significant for the selection of trees in either silvicultural approach, neither as a main factor nor in interaction with the background. In general, the probability of selecting a tree was higher for small trees. Nonetheless, in the SA, female foresters were more prone than male foresters to select trees with DBH larger than $45 \mathrm{~cm}$. Those without forestry background showed the opposite pattern; there was an increased probability of selecting beech trees with DBH higher than $25 \mathrm{~cm}$ in the SA (Fig. 6, upper panel). The probability of marking Norway spruce individuals was higher in the CA for both males and females. The probability of marking individuals with DBH larger than $25 \mathrm{~cm}$ was higher for non-foresters (Fig. 6, middle panel). The probability of selecting silver fir trees was higher in the $\mathrm{SA}$, if trees had diameters larger than $55 \mathrm{~cm}$, as was the case for the rest of the species. This probability was higher for females than for males. In the SA, this probability was clearly higher for male non-foresters (Fig. 6, bottom panel). 


\subsubsection{Internal consistency and conditional agreement}

According to the classification proposed by Stoyan et al. (2018), the tree marking agreement within each group was slight in the CA for both educational backgrounds (kappa values between 0.10 and 0.33 ). The greatest agreement was within male foresters in the $\mathrm{CA}(K=0.30)$, which contrasts the low agreement detected within female foresters (Table 3 ). Separation by age groups in the forester category showed similar agreement. Non-foresters had similar agreement irrespective of age and gender. Agreement in the SA was very poor for those with forestry background across genders and ages (Table 3).

The agreement between the raters' groups and the expert varied from poor to slight. In the CA, the agreement between the expert and the male foresters was significantly higher than the agreement between the expert and the female foresters. The rest of the comparisons between raters with different backgrounds and sociodemographic characteristics and the expert were non-significant (Figs. 7 and 8, upper panels). There was slight conditional agreement between the expert and the group in terms of the trees that were marked, with higher values in the CA. There were nonsignificant differences in the agreement between the expert and the raters in terms of the raters' background, gender, or age (Figs. 7 and 8, upper panels).

\section{Discussion}

Existing experimental works show that the implementation and adoption of new forestry approaches are highly dependent on the clear definition of objectives and prescriptions as well as the previous experience of practitioners (O'Hara et al. 2012; Vítková et al. 2016).

The adoption of a new silvicultural method depends on the human behavior associated with understanding the method. There are few studies analyzing human behavior in forestry operations. Vítková et al. (2016) tested the judgment of forestry experts and novices in marking trees following the continuous cover forestry approach (CCF), which is considered an alternative to conventional forestry (Pommerening and Murphy 2004; Pukkala and von Gadow 2012). Contrary to Vítková et al. (2016), our intention was to test if learned methods during formal studies influenced marking decisions and if sociodemographic variables (gender and age) of raters would exert some influence. The inclusion of a non-forester group was based on the assumption that they represent the final forestry decision makers. If the non-forester group differed from foresters, this would mean that the perception of the former is clearly different from the professional perception of the latter when it comes to the alternative system. Many studies are examining stakeholders' perceptions and decision-making based on their social positions at communities or their roles in forest management (Fig. 10). Other studies are exploring how gender affects land use decisions and forest governance (Agarwal 2017; Follo et al. 2017; Sunderland et al., 2014; Villamor et al., 2014). Few studies are taking into account how gender and age influence decisionmaking and behavior in forestry.

Our results suggested that foresters in our study did not distinguish between the SA and crown thinning, a type of thinning that is usually taught at the university and is consistent with the CCF. This evidence suggests that professionals associated the SA with previously known alternative silvicultural methods. However, the $\mathrm{CCF}$ and the SA differ in the manner trees are selected. In the $\mathrm{CCF}$, trees are selected in such a manner that soil is never exposed, thus maintaining a continuous canopy cover (Pommerening and Murphy 2004). The typical silvicultural regime for the $\mathrm{CCF}$ is single tree selection resulting in an uneven-aged or multi-aged stand structure, which is considered more resistant and resilient (OHara and Ramage, 2013). Unevenness requires a final equilibrium size distribution (O'Hara 2004). Instead, in the case of the SA, no final distribution is preconceived; harvest is guided by the objective of favoring natural regeneration as a means of increasing diversity and complexity of forest stands, with the only limit being the minimum standing growing stock required (Nocentini et al. 2017).

Conventional forest management is strongly based on desired future conditions (DFCs) and predictable outcomes in homogenous forests, such as FT-1 in the marteloscope used in our study; however, it results in variable decisions in more complex situations (FT-2). The lack of a target diameter distribution in the SA or a more holistic framework of DFC could be a hurdle for the adoption of the method, owing to the general preference of foresters for clear and simple marking rules. However, the DFC concept in ecosystem management is being questioned because of the unpredictability of natural events and social preferences towards ecosystems in a changing environment (Matonis et al. 2016), which are in line with the conceptual bases of the SA (Nocentini et al. 2017).

Our findings expand results found by Vítková et al. (2016) who concluded that foresters faced with thinning operations without specific instructions performed the method more familiar to them. In our study, even with instructions on how to apply the SA, foresters biased their 
decisions towards a well-known marking method. This suggests that extensive training is required when a new forestry method is developed.

Our study showed that some tree sizes and species were preferred more over others by markers; this preference was dependent on the silvicultural method used and modulated by gender. The discrepancies in individual tree selection did not lead to differences at the stand level but they could compromise the multifunctionality of the forests if certain species that promote specific ecosystem services are extensively removed (Isbell et al. 2011), pointing out the need to link quantitatively the minimum stand growing stock concept to multifunctionality and tree species diversity.

At the stand level, the raters' consistency and intensity of marking was more similar to those of the experts in the CA; this similarity was higher in quadrants with fewer species (FT-1) indicating that foresters, non-foresters, and experts reached the stand-level objective more easily in simplified structures. This shows how all groups are more prone and somehow more comfortable in making decisions in homogenous stands, an issue that is behind the silvicultural tendency to simplify forest structures (Puettmann et al. 2008). However, at the tree level, the consistency and agreement was very low compared to other studies on other forest ecosystems (Vítková et al. 2016; Pommerening et al. 2018). The poor to slight agreement within groups and between the expert and the raters indicated that individual tree choices are rather "personal" and that the same silvicultural goal at the stand level can be reached by different individual pathways.

Studies involving marteloscopes have several caveats. First, experts' choices are not unbiased, as their background and sociodemographic features may condition their decisions. We partially compensated for this issue by inviting two experts (one female and one male) per silvicultural approach. In the case of age, the experts may have been conditioned by their long professional careers, as experts were over 40 years old. Second, the number of people who act as raters should be kept low. From a logistics point of view, it is very costly to transport and train people and conduct the marking experiment in a single day or in consecutive days. Additionally, the forest condition and perceptions on how the forest looks like may change due to weather conditions if marking is conducted in separate days. We kept the number of markers low ( 12 by background type and 6 by background and age or gender) to reduce the duration of the experiment and the influence of environmental conditions on the selection of trees. We recognized that this implies a trade-off between the generality and interpretability of results. In our case, the interpretability was straightforward, whereas generality should be contemplated with caution. In this perspective, the large number of marteloscopes in Europe and elsewhere (Schuck et al. 2015; Pommerening et al., 2018) offers the possibility to replicate and expand our investigation, and increase the confidence and the power of the analyses proposed in the present study.

\section{Conclusions}

When foresters are facing a new method, they tend to apply the conventional method they are more familiar with. In our study, raters with forestry background made a clear distinction between the SA and the CA. At the stand level, they performed the CA with a high degree of similarity to experts. Non-foresters did not clearly differentiate between either method at the stand level (statement 1 correct). Learning a new method is highly conditioned by previously obtained knowledge. The agreement within groups and between the expert and the groups did not differ between the two silvicultural approaches; this agreement was slight in the CA and slight to poor in the SA (statement 2 partially correct). Gender had a more important effect than age, affecting the average intensity at the stand level and the agreement in the CA (statement 2 partially correct). The individual tree selection differed between approaches and between backgrounds, and it was based on characteristics such as belonging to a gender group within the same background group (statement 3 partially correct).

Acknowledgments SGAIP-CSIC provided valuable support on the statistical analyses of data. ABO thanks CREA and DAGRI for their hospitality during his scientific visit and Prof. Orazio Ciancio for his explanations on systemic silviculture.

Funding information LIFE+ PProSpoT (Policy and Protection of Sporadic tree species in Tuscany forests, LIFE09 ENV/IT/000087).

Data availability The datasets generated and/or analyzed during the current study are available in the Digital.CSIC repository, https://oi.org/10. 20350/digitalCSIC/10574.

\section{Compliance with ethical standards}

Conflict of interest The authors declare that they have no conflict of interest. 


\section{Annex}

Table 4 Guidelines for marking according to the silvicultural approaches tested

FT-1

50-year-old Norway spruce afforestation with broadleaves
FT-2

Mixed native broadleaves-conifers understory reinitiation phase

\section{Conventional approach}

\begin{tabular}{|c|c|}
\hline Aims & $\begin{array}{l}\text { (i) Regulate spatial distribution of remaining trees to guarantee } \\
\text { adequate growing space } \\
\text { (ii) Regulate the species mixture maintaining silver fir }\end{array}$ \\
\hline $\begin{array}{l}\text { Marking } \\
\text { rules }\end{array}$ & $\begin{array}{l}\text { (i) Low thinning } \\
\text { (ii) Eliminate all damaged, sick, and dead trees } \\
\text { (iii) Favor all the sporadic and fruit bearing broadleaves }\end{array}$ \\
\hline Intensity & $\begin{array}{l}<30 \% \text { number of trees; }<20 \% \text { timber volume } \\
\text { Systemic approach }\end{array}$ \\
\hline Aims & $\begin{array}{l}\text { (i) Increase stand stability by gradually reducing tree density } \\
\text { (ii) Where soil conditions are favorable prepare the stand for } \\
\text { natural regeneration of fir and local broadleaves. }\end{array}$ \\
\hline $\begin{array}{l}\text { Marking } \\
\text { rules }\end{array}$ & $\begin{array}{l}\text { (i) Low thinning } \\
\text { (ii) Eliminate all damaged, sick, and dead Norway spruce trees } \\
\text { (iii) Favor all the sporadic broadleaves }\end{array}$ \\
\hline Intensity & $\begin{array}{l}<25 \% \text { number of trees; }<15 \% \text { timber volume } \\
\text { Additional thinning types performed by experts }\end{array}$ \\
\hline $\begin{array}{l}\text { Low } \\
\text { thin- } \\
\text { ning }\end{array}$ & $\begin{array}{l}\text { eliminate all suppressed and smaller trees up to the maximum } \\
\text { allowed intensity }(<30 \% \text { number of trees; }<20 \% \text { timber } \\
\text { volume) }\end{array}$ \\
\hline $\begin{array}{l}\text { Crown } \\
\text { thin- } \\
\text { ning }\end{array}$ & $\begin{array}{l}\text { Reduce density of the upper canopy by eliminating some } \\
\text { dominant and codominant trees but leaving all the smaller and } \\
\text { suppressed trees }\end{array}$ \\
\hline
\end{tabular}

(i) Regulate spatial distribution of the upper-storey trees

(ii) Select future crop trees

(iii) Balance the conifer-broadleaved mixture

(i) Thinning of the upper-storey trees favoring selected crop trees

(ii) Eliminate all damaged, sick, and dead trees

(iii) Favor all the sporadic and fruit bearing broadleaves

$<30 \%$ of number of trees; $<20 \%$ of timber volume

(i) Favor gradual transformation towards mixed uneven aged stands without a predefined composition or structure

(ii) Reduce species and structure simplification and regularization

(iii) Favor natural regeneration

(i) Quadrants with diversified composition and structure: eliminate all trees that are hindering natural regeneration

(ii) Quadrants with uniform structure and composition: eliminate very small groups of the biggest trees (2-4 trees) to create small gaps $\left(50-100 \mathrm{~m}^{2}\right)$ to stimulate natural regeneration

In all cases, leave all dead standing trees with $\mathrm{DBH}>30 \mathrm{~cm}$

$<57 \mathrm{~m}^{3} \mathrm{ha}^{-1}$

Eliminate all suppressed and smaller trees up to the maximum allowed intensity ( $<30 \%$ number of trees; $<20 \%$ timber volume)

Reduce density of the upper canopy by eliminating some dominant and codominant trees but leaving all the smaller and suppressed trees

Table 5 Fixed-effect type III test for the mixed model and likelihood ratio test

\begin{tabular}{lll}
\hline Effect & $F$ value & $\operatorname{Pr}>\mathrm{F}$ \\
\hline Evaluator & 8.8 & 0.0 \\
Criteria & 40.4 & $<.0001$ \\
Evaluator x criteria & 13.4 & 0.0 \\
Sex (evaluator) & 4.7 & 0.0 \\
Background (evaluator) & 24.3 & 0.0 \\
Likelihood ratio test & Chi-squared & $\operatorname{Pr}>$ ChiSq \\
& 57.0 & $<.0001$ \\
\hline
\end{tabular}


Table 6 Logistic fitting of the probability of selection for harvest of individual trees

\begin{tabular}{|c|c|c|c|c|c|c|c|c|c|}
\hline \multicolumn{5}{|l|}{ Traditional } & \multirow{2}{*}{$\begin{array}{l}\text { Systemic } \\
\text { Parameter }\end{array}$} & & & & \\
\hline Parameter & $\begin{array}{l}\text { Estimate } \\
\text { squared } \mathrm{P}\end{array}$ & $\begin{array}{l}\text { standard e } \\
r>\text { chi-squ }\end{array}$ & $\begin{array}{l}\text { rror Wal } \\
\text { aared }\end{array}$ & d's chi- & & \multicolumn{4}{|c|}{$\begin{array}{l}\text { Estimate standard error Wald's chi- } \\
\text { squared } \operatorname{Pr}>\text { chi-squared }\end{array}$} \\
\hline Intercept & 1.6133 & 0.1595 & 102.3 & $<.0001$ & Intercept & 0.5773 & 0.172 & 11.2648 & 0.0008 \\
\hline $\mathrm{dbh}$ & -0.0839 & 0.00303 & 765.2 & $<.0001$ & $\mathrm{dbh}$ & -0.0525 & 0.00315 & 277.8642 & $<.0001$ \\
\hline Beech & -1.2887 & 0.1411 & 83.37 & $<.0001$ & Beech & -1.0628 & 0.15 & 50.209 & $<.0001$ \\
\hline Maple & -1.6128 & 0.1452 & 123.4 & $<.0001$ & Maple & -1.3246 & 0.1559 & 72.2055 & $<.0001$ \\
\hline Norway spruce & -0.9171 & 0.1409 & 42.4 & $<.0001$ & Norway spruce & -0.5757 & 0.1495 & 14.8247 & 0.0001 \\
\hline Others & -1.5632 & 0.1461 & 114.5 & $<.0001$ & Others & -1.1608 & 0.1563 & 55.1514 & $<.0001$ \\
\hline Sex (female) & 0.1065 & 0.0395 & 7.3 & 0.007 & Background (forester) & -0.7279 & 0.0498 & 213.58 & 0.007 \\
\hline $\begin{array}{l}\text { Background x sex (forester } \\
\text { female) }\end{array}$ & -0.3456 & 0.0469 & 54.2 & $<.0001$ & $\begin{array}{l}\text { Background x sex (forester } \\
\text { female) }\end{array}$ & -0.1406 & 0.063 & 4.979 & 0.0257 \\
\hline
\end{tabular}

Systemic - Non Foresters, female

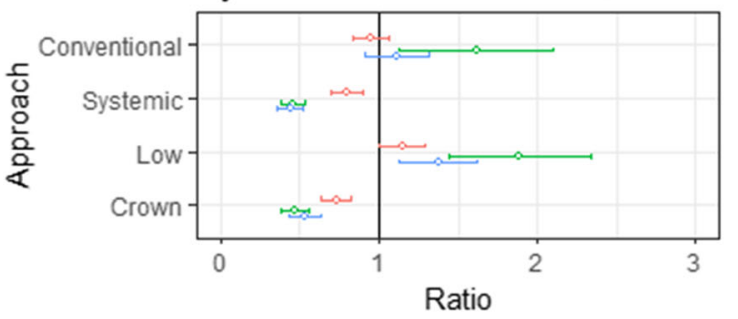

Conventional - Non Foresters, female
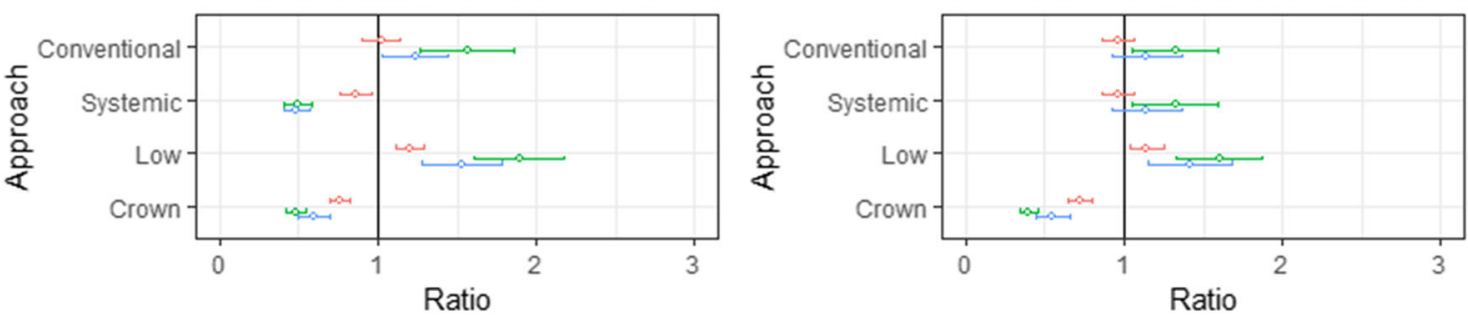

Quadrants $\multimap$ Forest Type $1 \multimap$ Forest Type $2 \multimap$ All quadrants

Fig. 9 Sex effect on the thinning type stakeholder-expert ratio performed by non-foresters after systemic (upper panels) and conventional approaches (bottom panels) in Abetone Pistoiese (Central Italy) 
Systemic - Non Forester, above 40

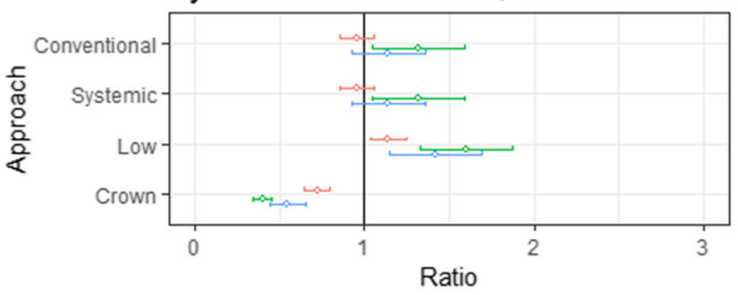

Conventional - Non Forester, above 40

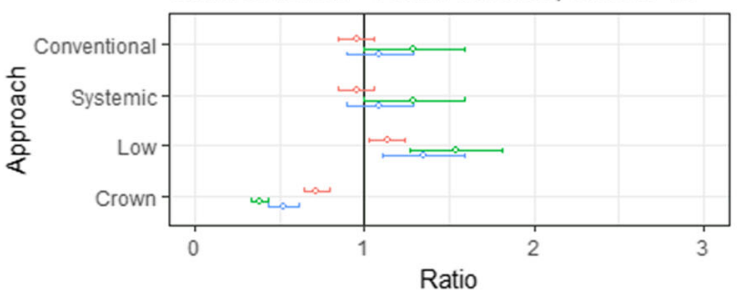

Systemic - Non Forester, under 40

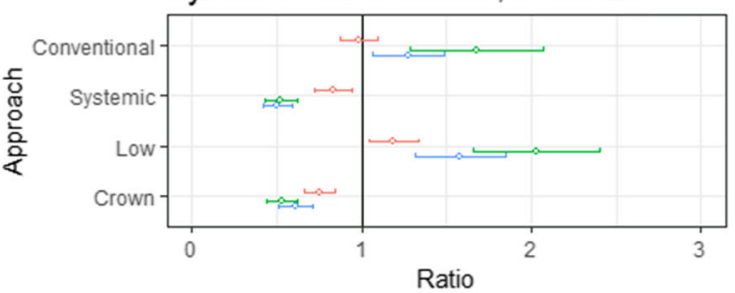

Conventional - Non Foresters, under 40

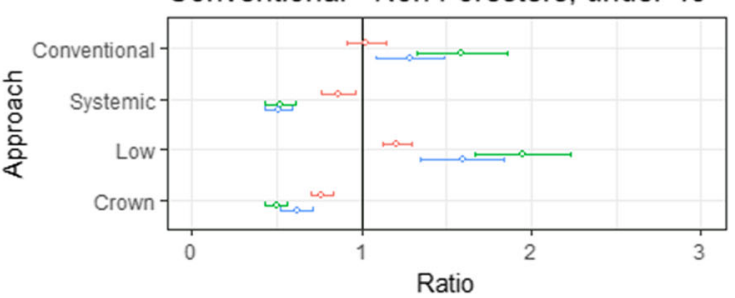

Quadrants $\because$ Forest Type $1 \multimap$ Forest Type $2 \leadsto$ All quadrants

Fig. 10 Age class effect on the thinning type stakeholder-expert ratio performed by non foresters after systemic (upper panels) and conventional approaches (bottom panels) in Abetone Pistoiese (Central Italy)

Fig. 11 Mean BA ratio comparisons between a sex and type of participants and $\mathbf{b}$ background and type of participants
A

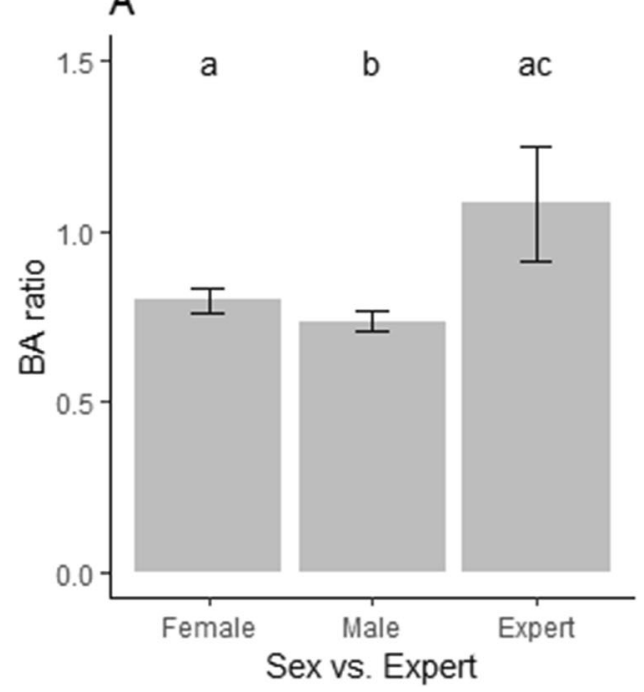

B

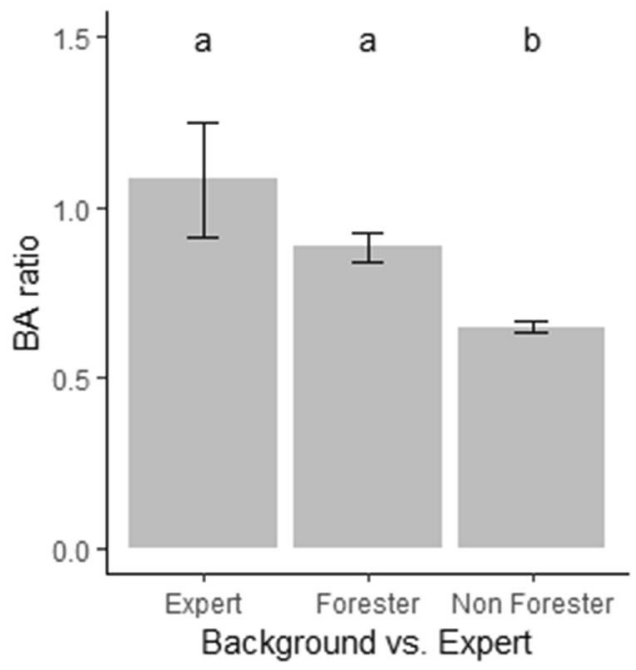




\section{References}

Angelstam P, Axelsson R, Elbakidze M et al (2011) Knowledge production and learning for sustainable forest management on the ground: pan-European landscapes as a time machine. Forestry 84:581-596. https://doi.org/10.1093/forestry/cpr048

Ashton M, Kelty MJ (2018) The practice of silviculture: applied forest ecology, 10th Editi edn. Wiley and Sons, Inc., Hoboken, NJ

Bishop YM, Holland PW, Fienberg SE (2007) Discrete multivariate analysis: theory and practice, Reprint of 1975 ed. Springer, New York, NY

Bourne LE, Kole JA, Healy AF (2014) Expertise: defined, described, explained. Front Psychol 5:4-6. https://doi.org/10.3389/fpsyg. 2014.00186

Bravo-Oviedo A, Marchi M, Travaglini D, Pelleri F, Manetti MC, Corona P, Cruz F, Bravo F, Nocentini S (2020) Adoption of new silvicultural methods in Mediterranean forests: the influence of educational background and socio-demographic factors on markers decisions. V1. Digital.CSIC repository. [dataset]. https://doi.org/10.20350/ digitalCSIC/10574

Cardinale BJ, Duffy JE, Gonzalez A et al (2012) Biodiversity loss and its impact on humanity. Nature 489:326-326. https://doi.org/10.1038/ nature 11373

Eggers J, Lämås T, Lind T, Öhman K (2014) Factors influencing the choice of management strategy among small-scale private forest owners in Sweden. Forests 5:1695-1716. https://doi.org/10.3390/ f5071695

Fleiss JL, Levin B, Paik MC (2013) Statistical methods por rates and proportions, Third Ed. John Wiley \& Sons, Inc., Hoboken, NJ

Follo G, Lidestav G, Ludvig A et al (2017) Gender in European forest ownership and management: reflections on women as "new forest owners". Scand J For Res 32:174-184. https://doi.org/10.1080/ 02827581.2016 .1195866

FOREST EUROPE (2015) State of Europe's Forests 2015. Ministerial conference on the protectionof forests in Europe. FOREST EUROPE Liaison Unit Madrid, www.foresteurope.org, 312 p.

Gamer M, Lemon J, Fellows I, Singh P (2019) irr: Various Coefficients of Interrater Reliability and Agreement. R package version 0.84.1. https://CRAN.Rproject.org/package=irr

Harding SG (1986) The science question in feminism. Cornell Unviersity Press, Ithaca, NY

Isbell F, Calcagno V, Hector A et al (2011) High plant diversity is needed to maintain ecosystem services. Nature 477:199-202. https://doi. org/10.1038/nature10282

Kerr G, Haufe J (2011) Thinning practice a Silvicultural guide. Version 1.0 , Forestry Commission, $54 \mathrm{p}$

Lidestav G, Ekström M (2000) Introducing gender in studies on management behaviour among non-industrial private forest owners. Scand J For Res 15:378-386. https://doi.org/10.1080/028275800448011

Marchetti M, Vizzarri M, Lasserre B et al (2014) Natural capital and bioeconomy : challenges and opportunities for forestry. Ann Silvic Res 38:62-73

Matonis MS, Binkley D, Franklin J, Johnson KN (2016) Benefits of an "undesirable" approach to natural resource management. J For 114: 658-665. https://doi.org/10.5849/jof.15-140

Nocentini S, Buttoud G, Ciancio O, Corona P (2017) Managing forests in a changing world : the need for a systemic approach. A review. For Syst 26:1-15

O'Hara KL (2004) Stocking control concepts in uneven-aged silviculture. Forestry 77:131-143. https://doi.org/10.1093/forestry/77.2.131

O'Hara KL, Leonard LP, Keyes CR (2012) Variable-density thinning and a marking paradox: comparing presciption protocols to attain stand variability in coast redwood. West J Appl For 27:143-149
OHara KL, Ramage BS (2013) Silviculture in an uncertain world: utilizing multi-aged management systems to integrate disturbance. Forestry:86. https://doi.org/10.1093/forestry/cpt012

Piussi P (1994) Selvicoltura generale. UTET, Turin

Pommerening A, Murphy ST (2004) A review of the history, definitions and methods of continous cover forestry with special attention to afforestation and restocking. Forestry 77:27-44

Pommerening A, Pallarés Ramos C, Kędziora W et al (2018) Rating experiments in forestry: how much agreement is there in tree marking? PLoS One 13:1-20. https://doi.org/10.1371/journal.pone. 0194747

Pretzsch H, Zenner EK (2017) Toward managing mixed-species stands: from parametrization to prescription. For Ecosyst 4:19. https://doi. org/10.1186/s40663-017-0105-Z

Puettmann KJ, Coates KD, Messier C (2008) A critique of silviculture: managing for complexity. Island Press, Washington DC

Puettmann KJ, Wilson SM, Baker SC et al (2015) Silvicultural alternatives to conventional even-aged forest management - what limits global adoption? For Ecosyst 2:2-8. https://doi.org/10.1186/ s40663-015-0031-x

Pukkala T, von Gadow K (eds) (2012) Continous cover forestry. Springer, Dordrecht

R Core Team (2018) R: a language and environment for statistical computing. https://www.R-project.org/

Rodriguez de Prado D, Bravo F, Ordóñez AC (2017) Smartelo, una herramienta informática para el cálculo, gestión y presentación de datos en parcelas forestales. In: $7^{\circ}$ Congreso Forestal Español, no. 7CFE01-247. SECF, Sociedad Española de Ciencias Forestales, Plasencia, Cáceres, España, pp 1-11. http://secforestales.org/ publicaciones/index.php/congresos_forestales/article/view/19037

Schuck A, Kraus D, Krumm F, Schmitt H (2015) Integrate+ Marteloscopes-calibrating silvicultural decision making. Integrate+ Technical Paper, No 1, European Forest Institute. www. integrateplus.org

Smith DM, Larson BC, Kelty MJ, Ashton PMS (1997) The practice of silviculture. Applied forest ecology, 9th edn. John Wiley and Sons, INC., New York

Spinelli R, Magagnotti N, Pari L, Soucy M (2016) Comparing tree selection as performed by different professional figures. For Sci 62:213219. https://doi.org/10.5849/forsci.15-062

Stoyan D, Pommerening A, Hummel M, Kopp-Schneider A (2018) Multiple-rater kappas for binary data: models and interpretation. Biom J 60:381-394. https://doi.org/10.1002/bimj.201600267

Sunderland T, Achdiawan R, Angelsen A et al (2014) Challenging perceptions about men, women and forest product use: a global comparative study. World Dev 64:S56-S66

Tanner MA, Young MA (1985) Modeling agreement among raters. J Am Stat Assoc 80:175-180

Umaerus P, Högvall Nordin M, Lidestav G (2019) Do female forest owners think and act "greener"? For Policy Econ 99:52-58. https://doi.org/10.1016/j.forpol.2017.12.001

Villamor GB, Desrianti F, Akiefnawati R, Amaruzaman S, Noordwijk M (2014) Gender influences decisions to change land use practices in the tropical forest margins of Jambi, Indonesia. Mitig Adapt Strateg Glob Chang 19:733-755. https://doi.org/10.1007/s11027-0139478-7

Vítková L, Dhubháin ÁN, Pommerening A (2016) Agreement in tree marking: what is the uncertainty of human tree selection in selective forest management? For Sci 62:288-296. https://doi.org/10.5849/ forsci.15-133

Publisher's note Springer Nature remains neutral with regard to jurisdictional claims in published maps and institutional affiliations. 